\title{
Karakteristik Arus-Tegangan Semikonduktor Copper Oxide Didoping dengan Zinc Oxide Sebagai Sensor Gas Hidrogen
}

\author{
Zulfikri Syafnur*, Elvaswer \\ Jurusan Fisika, FMIPA, Universitas Andalas, Kampus Limau Manis Padang, 25163 \\ *z26syafnur@gmail.com
}

\begin{abstract}
ABSTRAK
Telah dilakukan karakterisasi sensor gas hidrogen berupa pelet dengan bahan utama $\mathrm{CuO}$ yang didoping dengan $\mathrm{ZnO}$. Pelet dibuat dengan variasi konsentrasi doping $\mathrm{ZnO}$. Sensor gas hidrogen dibuat dengan menggunakan metode reaksi dalam keadaan padat. Sensor gas hidrogen diuji pada temperatur ruang dengan melihat karakteristik I-V, sensitivitas, konduktivitas, waktu respon, dan kristalinitas. Karakteristik I-V menunjukkan bahwa sampel dengan doping $\mathrm{ZnO}$ sebanyak $8 \%$ mol memiliki sensitivitas tertinggi yaitu 4,59 pada tegangan kerja 21 Volt. Nilai konduktivitas tertinggi dimiliki sampel CuO doping $2 \%$ mol $\mathrm{ZnO}$ yaitu $21,91 \times 10^{-5} / \Omega \mathrm{m}$ pada lingkungan hidrogen. Waktu respon sampel $\mathrm{CuO}$ didoping $8 \% \mathrm{~mol} \mathrm{ZnO}$ adalah 45 s pada tegangan 21 Volt. Hasil XRD menunjukkan ukuran kristal $\mathrm{CuO}$ didoping $8 \%$ mol $\mathrm{ZnO}$ lebih besar dibandingkan dengan bahan $\mathrm{CuO}$ tanpa doping. Sensor gas hidrogen telah mampu membedakan kondisi di lingkungan hidrogen dengan kondisi di lingkungan udara, dengan sensitivitas yang tinggi dan waktu respon yang singkat. Sensor yang paling optimal digunakan adalah $\mathrm{CuO}$ didoping $8 \%$ mol $\mathrm{ZnO}$.
\end{abstract}

Kata kunci : sensor gas hidrogen, $\mathrm{CuO}, \mathrm{ZnO}$, sensitivitas, waktu respon

\section{ABSTRACT}

The hydrogen gas sensor in the form of pellets made of $\mathrm{CuO}$ doped with $\mathrm{ZnO}$ was characterized. The pellets were made by doping $\mathrm{ZnO}$ into $\mathrm{CuO}$. The hydrogen gas sensor was fabricated using solid state reaction method. Hydrogen gas sensor was tested at room temperature by investigating the I-V characteristic, sensitivity, conductivity, response time, and crystallnity. I-V characteristics indicates that the sample doped with $8 \%$ mol $\mathrm{ZnO}$ shows the highest sensitivity, that is 4.59 at 21 Volt. The sample of $\mathrm{CuO}$ doped with $2 \%$ mol $\mathrm{ZnO}$ has the highest conductivity that is $21,91 \times 10^{-5} / \mathrm{\Omega m}$ in hydrogen environment. The response time of the $\mathrm{CuO}$ doped with $8 \% \mathrm{~mol} \mathrm{ZnO}$ sample at 21 Volt is $45 \mathrm{~s}$. XRD results indicate that the crystal size of $\mathrm{CuO}$ doped with $8 \% \mathrm{~mol} \mathrm{ZnO}$ is larger than that of non-doped $\mathrm{CuO}$. The hydrogen gas sensor is able to differentiate the state wheter in hydrogen environment or in air environment, with high sensitivity and short response time. The sample of $\mathrm{CuO}$ doped with $8 \% \mathrm{~mol} \mathrm{ZnO}$ is the best sensor to be used.

Keywords : hydrogen gas sensor, $\mathrm{CuO}, \mathrm{ZnO}$, sensitivity, response time

\section{PENDAHULUAN}

Hidrogen merupakan unsur yang melimpah di alam semesta. Hidrogen tidak berwarna, tidak berbau, bersifat non-logam, dan bervalensi tunggal. Hidrogen digunakan sebagai bahan bakar pada kendaraan, dan banyak digunakan pada pembangkit listrik sebagai pendingin generator. Polusi udara yang ditimbulkan oleh bahan bakar hidrogen jauh lebih rendah dibandingkan bahan bakar fosil. Hidrogen dikemas dalam tabung-tabung baja dan disimpan dalam ruangan khusus. Hidrogen akan meledak jika disulut dengan api dan terbakar pada suhu $560{ }^{\circ} \mathrm{C}$. Pembakaran hidrogen-oksigen murni memancarkan gelombang ultraviolet dan hampir tidak terlihat oleh mata manusia sehingga kebocoran gas hidrogen sulit untuk dideteksi secara visual. Untuk mendeteksi kebocoran gas hidrogen, diperlukan sensor gas hidrogen (Aygun dan Cann, 2005).

Sensor gas yang dikembangkan pada umumnya berbentuk lapisan tipis semikonduktor logam oksida. $\mathrm{TiO}_{2}$ (Titanium Dioxide), $\mathrm{ZnO}$ (Zinc Oxide), $\mathrm{CuO}$ (Copper Oxide), dan ITO (Indium Tin Oxide) telah dikembangkan sebagai pendeteksi gas $\mathrm{H}_{2}$ (Hydrogen), $\mathrm{CO}$ (Carbon Monoxide), $\mathrm{CH}_{4}$ (Methane), dan hidrokarbon lainnya (Wang, dkk., 1998). Sensor dengan bahan semikonduktor logam oksida yang peka terhadap gas dan dapat merubah sifat fisisnya ketika berinteraksi dengan gas. Bahan semikoduktor logam oksida dapat mendeteksi berbagai gas karena bahan oksida yang bereaksi dengan gas akan mengalami perubahan stoikiometri butiran bahan. Perubahan stoikiometri tersebut dapat mengakibatkan perubahan konduktivitas bahan semikonduktor (Akbar, 1997). 
Penelitian tentang sensor gas hidrogen sebelumnya telah dilakukan oleh Hoa, dkk (2010) yang menggunakan bahan $\mathrm{CuO}$ dalam bentuk film tipis. Sensitivitas tertinggi sebesar 3,72 didapatkan pada temperatur $250{ }^{\circ} \mathrm{C}$. Fardindoost, dkk (2010) juga telah melakukan penelitian dari bahan semikonduktor paladium $(\mathrm{Pd})$ yang didoping tungsten trioksida $\left(\mathrm{WO}_{3}\right)$ menggunakan metoda sol-gel, dan hasilnya menunjukkan bahwa bahan tersebut dapat mendeteksi gas hidrogen dengan waktu respon $100 \mathrm{~s}$ pada temperatur $100{ }^{\circ} \mathrm{C}$. Liu, dkk. (2015) juga telah melakukan penelitian sensor gas hidrogen dari bahan molybdenum disulfida $\left(\mathrm{MoS}_{2}\right) / \mathrm{Silikon}(\mathrm{Si})$ heterokontak. Waktu respon yang didapatkan sebesar $105 \mathrm{~s}$ pada arus 0,4 $\mathrm{mA}$ dan 1,3 mA dengan tegangan sebesar $-5 \mathrm{~V}$ dan $5 \mathrm{~V}$.

$\mathrm{ZnO}$ merupakan bahan yang akan digunakan sebagai pendoping $\mathrm{CuO}$. Bahan $\mathrm{ZnO}$ sering digunakan sebagai bahan sensor gas, karena $\mathrm{ZnO}$ merupakan bahan yang memilki stabilitas termal yang baik, sensitivitas yang tinggi, mudah dalam pembuatan, sifat listrik yang dibutuhkan sebagai sensor gas, dan temperatur kerja yang sedang (Cao, dkk. 2009). Bahan CuO memiliki sifat serapan gas, sifat kimia yang sesuai untuk aplikasi katalis dan sebagai sensor gas (Wismadi, 2001).

Pada penelitian ini telah dibuat sensor gas hidrogen dari bahan semikonduktor $\mathrm{CuO}$ yang didoping dengan $\mathrm{ZnO}$ dengan metode reaksi dalam keadaan padat (solid state reaction) yang berbentuk pelet. Sensor dari bahan $\mathrm{CuO}$ doping $\mathrm{ZnO}$ diharapkan dapat memiliki sensitivitas yang tinggi terhadap gas hidrogen dan dapat beroperasi pada temperatur ruang.

\section{METODE}

\subsection{Persiapan Pembuatan Pelet $\mathrm{CuO}$ didoping $\mathrm{ZnO}$}

Pada penelitian ini dibuat pelet dengan enam variasi persentase doping $\mathrm{ZnO}$ (merck, 99\%) yaitu 0\%, 2\%, 4\%, 6\%, 8\%, dan 10\% mol terhadap bahan dasar $\mathrm{CuO}$ (merck, 99\%). Sampel pelet yang diuji memiliki diameter $1,07 \mathrm{~cm}$ dan ketebalannya $0,25 \mathrm{~cm}$.

Reaksi kimia yang terjadi pada penelitian ini :

$$
x \mathrm{ZnO}+_{(1-x)} \mathrm{CuO} \longrightarrow \mathrm{Zn}_{x} \mathrm{Cu}_{(1-x)} \mathrm{O}
$$

dimana $x$ adalah fraksi mol doping yang ditambahkan. Sampel digerus selama 30 menit agar sampel menjadi halus, dan dikalsinasi pada suhu $500{ }^{\circ} \mathrm{C}$ selama 4 jam. Setelah proses kalsinasi bahan digerus kembali, agar butir-butir yang menggumpal menjadi lebih halus. Bahan dikompaksi sehingga berbentuk pelet, kemudian pelet di-sintering pada suhu $600{ }^{\circ} \mathrm{C}$ selama 4 jam.

\subsection{Karakterisasi Sensor Gas Hidrogen}

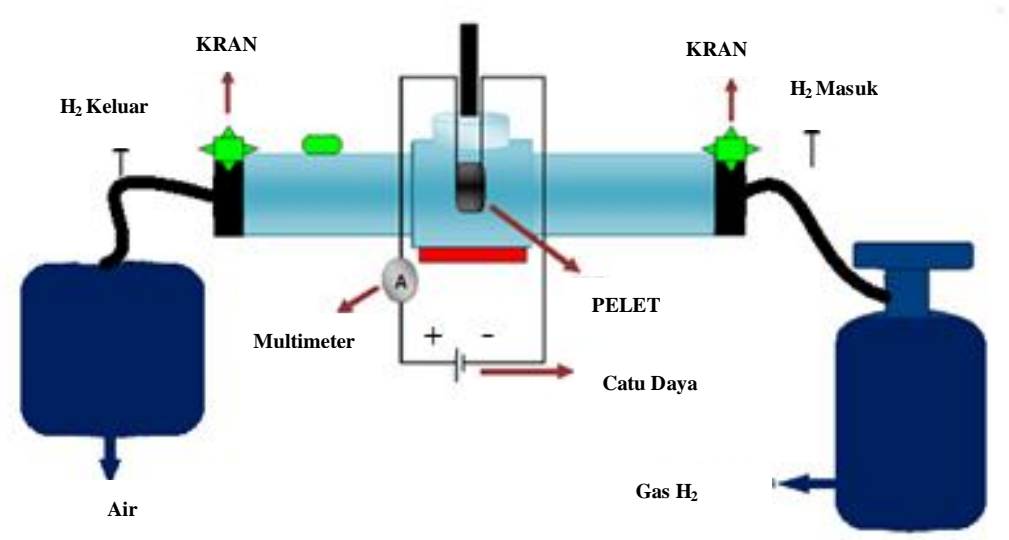

Gambar 1 Skema rangkaian alat pengujian sensor hidrogen

Pelet yang telah di-sintering diuji performanya dengan skema rangkaian dapat dilihat pada Gambar 1. Skema di atas memperlihatkan bahwa alat pengujian berfungsi untuk mengalirkan gas hidrogen. Pelet dirangkai bias maju dengan menghubungkan salah satu elektroda dengan kutub positif sedangkan elektroda lainnya dengan kutub negative. Posisi elektroda dibalik ke pengukuran dengan bias mundur. Amperemeter dihubungkan secara seri 
dengan sumber tegangan dan pelet. Pengukuran bias maju dan bias mundur diberikan variasi tegangan dari -30 Volt sampai 30 Volt dengan kenaikan 3 Volt.

Karakteristik $I-V$ diukur untuk menentukan sensitivitas dan konduktivitas sensor. Nilai sensitivitas dan konduktivitas dihitung menggunakan persamaan (2) dan persamaan (3). Sensitivitas menunjukkan seberapa sensitif sensor dalam mendeteksi suatu gas. Nilai sensitivitas dapat ditentukan dengan menggunakan persamaan :

$$
s=\frac{I_{\text {hidrogen }}}{I_{\text {udara }}}
$$

dengan $I_{\text {hidrogen }}$ adalah arus pada lingkungan hidrogen $(\mu \mathrm{A}), I_{\text {udara }}$ adalah arus pada lingkungan udara $(\mu \mathrm{A})$, dan $S$ merupakan sensitivitas.

Konduktivitas menunjukkan kemampuan suatu bahan untuk mengalirkan arus listrik. Nilai konduktivitas dapat dihitung menggunakan persamaan :

$$
\sigma=\frac{L}{R A}
$$

dimana $\sigma$ konduktivitas listrik $(1 / \Omega . \mathrm{m}), R$ adalah resistansi $(\Omega), A$ adalah luas penampang $\left(\mathrm{m}^{2}\right)$, dan $L$ adalah ketebalan sampel (m).

XRD digunakan untuk melihat ukuran kristal dari sampel. Ukuran kristal dapat dihitung menggunakan persamaan :

$$
D=\frac{0,9 \lambda}{B \cos \theta}
$$

dimana $D$ adalah ukuran kristal, $\lambda$ adalah panjang gelombang sinar-X yang digunakan, $\theta$ adalah sudut Bragg, $B$ adalah lebar penuh garis difraksi pada saat intensitas setengah maksimum (Full Width Half Maximum, FWHM), dan 0,9 merupakan nilai konstanta material untuk partikel bulat.

\section{HASIL DAN DISKUSI}

\subsection{Karakteristik $I-V$ pada Lingkungan Hidrogen dan Udara}

Karakteristik $I$ - $V$ masing-masing sampel pada lingkungan hidrogen dan udara dapat ditampilkan sebagai grafik arus-tegangan. Karakterisasi $I-V$ dilakukan untuk sampel $\mathrm{CuO}$ tanpa doping dan $\mathrm{CuO}$ didoping dengan $\mathrm{ZnO}$, ditunjukkan pada Gambar 2.

Gambar 2 (a) memperlihatkan grafik karakteristik $I-V$ dimana arus pada lingkungan hidrogen hampir overlap dengan arus pada lingkungan udara. Hal ini disebabkan oleh $\mathrm{CuO}$ sebelum didoping mempunyai energi gap lebih besar dibandingkan setelah didoping sehingga elektron susah untuk melompat dari pita valensi ke pita konduksi.

Gambar 2 (b) dan (c) menunjukkan bahwa sampel $\mathrm{CuO}$ didoping dengan 2\% mol $\mathrm{ZnO}$ dan $4 \% \mathrm{~mol} \mathrm{ZnO}$, arus pada lingkungan hidrogen lebih tinggi dibandingkan arus pada lingkungan udara. Hal ini disebabkan oleh doping dapat menurunkan energi gap sehingga elektron mudah melompat dari pita valensi ke pita konduksi.

Gambar 2 (d) menunjukkan bahwa pada bias maju, reaksi hidrogen dengan oksida sudah terjadi dengan indikasi arus pada lingkungan hidrogen lebih tinggi dari arus pada lingkungan udara. Sedangkan pada bias mundur arus di lingkungan hidrogen hampir overlap dengan arus pada lingkungan udara. Hal ini disebabkan pada bias mundur daerah deplesi membesar dan reaksi hidrogen dengan oksida sedikit terjadi.

Gambar 2 (e) memperlihatkan sampel $\mathrm{CuO}$ yang didoping $8 \%$ mol $\mathrm{ZnO}$ arus pada lingkungan hidrogen tinggi naiknya jika dibandingkan dengan arus di lingkungan udara pada bias maju. Hal ini disebabkan oleh energi gap yang kecil sehingga mudah elektron melompat dari pita valensi menuju pita konduksi. Sampel $\mathrm{CuO}$ didoping $8 \% \mathrm{~mol} \mathrm{ZnO}$ menunjukkan rasio antara arus pada lingkungan hidrogen dengan arus pada lingkungan udara paling tinggi. Hal ini disebabkan karena permukaan sensor akan menyerap molekul-molekul hidrogen yang berada di udara. Molekul-molekul hidrogen yang teradsorbsi ini akan mengikat elektron bebas pada 
permukaan bahan sensor semikonduktor. Pengikatan elektron bebas menyebabkan lapisan deplesi pada antarmuka butir kristal mengecil.

Gambar 2 (f) menunjukkan sampel $\mathrm{CuO}$ didoping $10 \%$ mol $\mathrm{ZnO}$ didapatkan bahwa perbedaan arus pada lingkungan hidrogen dengan arus pada lingkungan udara mengecil kembali. Hal ini disebabkan doping yang berlebihan sehingga mengakibatkan elektron sulit untuk bergerak.
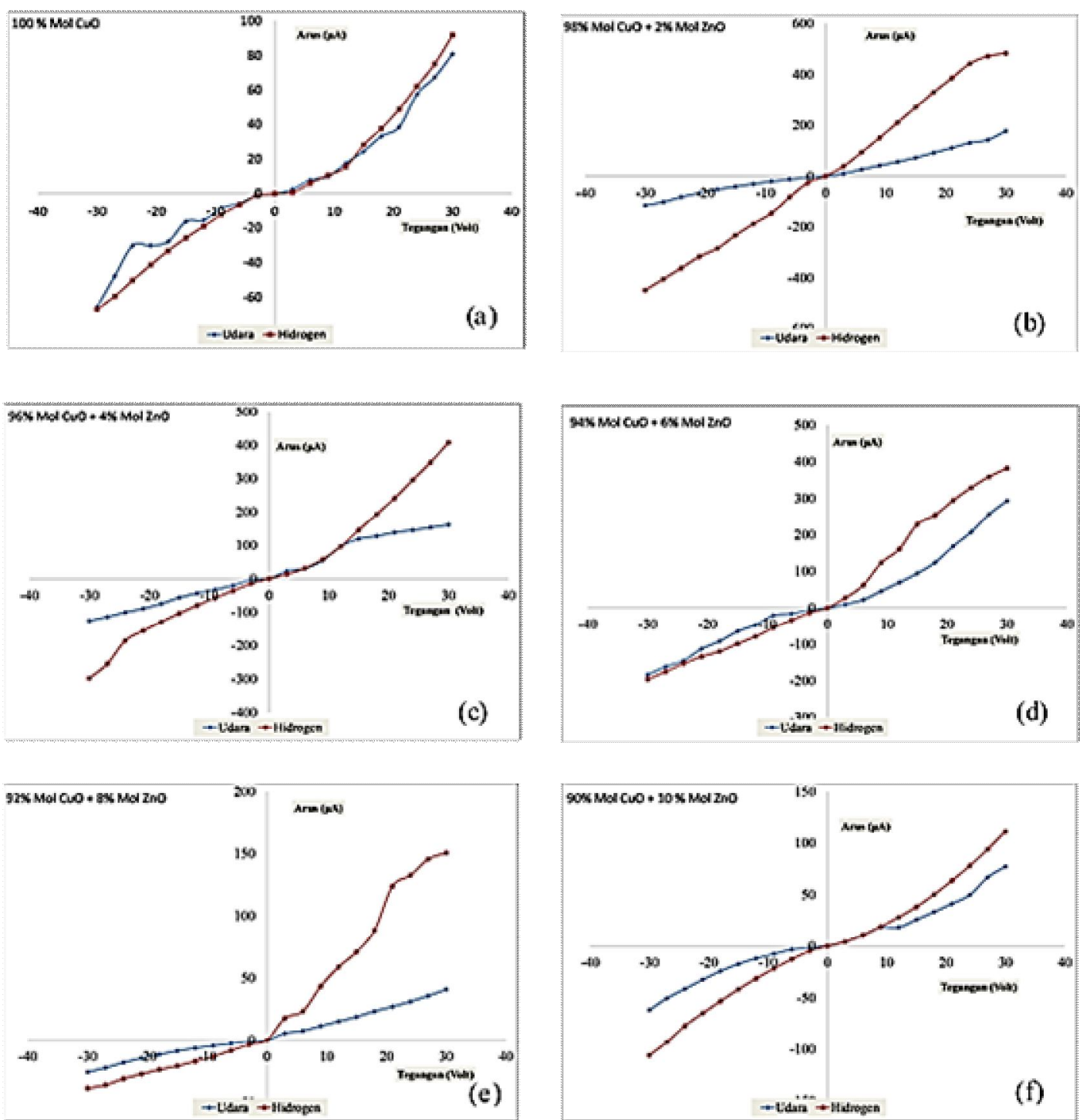

Gambar 2 Grafik karakteristik $I$ - $V$ pada lingkungan udara dan hidrogen

\subsection{Karakteristik Sensitivitas}

Sensitivitas sensor gas dapat diketahui berdasarkan grafik karakteristik I-V yang telah diperoleh dan dihitung menggunakan Persamaan 2. Perubahan nilai sensitivitas masing-masing sampel dapat dilihat pada Gambar 3. Dari Gambar 3 dapat dilihat bahwa sesitivitas tertinggi ditunjukkan pada sampel $\mathrm{CuO}$ didoping $8 \%$ mol $\mathrm{ZnO}$ yaitu sebesar 4,59 s pada tegangan operasional 21 Volt. Hal ini disebabkan doping dapat memeperkecil energi gap sehingga elektron mudah melompat dari pita velensi ke pita konduksi. Sensitivitas terendah didapatkan pada sampel $\mathrm{CuO}$ tanpa doping, hal ini disebabkan sampel sebelum didoping mempunyai energi gap yang besar. Pada sampel $\mathrm{CuO}$ didoping $10 \%$ mol $\mathrm{ZnO}$ sensitivitas menurun hal ini disebabkan oleh doping yang berlebihan mengakibatkan elektron sulit untuk bergerak. 


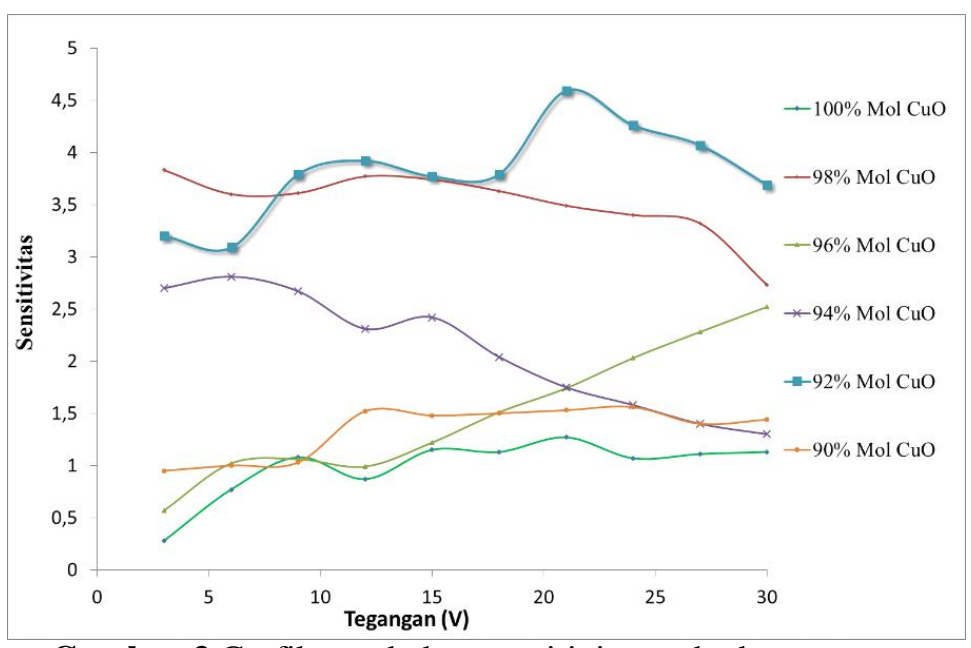

Gambar 3 Grafik perubahan sensitivitas terhadap tegangan

\subsection{Karakteristik Konduktivitas}

Nilai konduktivitas pada lingkungan udara maupun lingkungan hidrogen dapat dihitung menggunakan Persamaan 3. Nilai konduktivitas pada lingkungan hidrogen lebih besar dibandingkan dengan nilai konduktivitas pada lingkungan udara. Hal ini disebabkan oleh reaksi antara hidrogen dengan oksida pada permukaan partikel yang lebih besar pada lingkungan hidrogen dibandingkan pada lingkungan udara. Perubahan nilai konduktivitas sebelum dan sesudah dialiri gas hidrogen pada masing-masing sampel ditunjukkan pada Tabel 1.

Tabel 1 Perubahan konduktivitas pada lingkungan udara dan hidrogen

\begin{tabular}{lcc}
\hline \multirow{2}{*}{ Sampel } & \multicolumn{2}{c}{ Konduktivitas $\mathbf{( \mathbf { 1 0 } ^ { - 5 } / \mathbf { \Omega m } )}$} \\
\cline { 2 - 3 } & $\begin{array}{c}\text { Lingkungan } \\
\text { Udara }\end{array}$ & $\begin{array}{c}\text { Lingkungan } \\
\text { Hidrogen }\end{array}$ \\
\hline $\mathrm{CuO}$ & 2,11 & 2,42 \\
$\mathrm{CuO}+2 \% \mathrm{~mol} \mathrm{ZnO}$ & 5,36 & 21,91 \\
$\mathrm{CuO}+4 \% \mathrm{~mol} \mathrm{ZnO}$ & 7,07 & 11,60 \\
$\mathrm{CuO}+6 \% \mathrm{~mol} \mathrm{ZnO}$ & 7,69 & 13,30 \\
$\mathrm{CuO}+8 \% \mathrm{~mol} \mathrm{ZnO}$ & 1,36 & 4,46 \\
$\mathrm{CuO}+10 \% \mathrm{~mol} \mathrm{ZnO}$ & 2,23 & 3,76 \\
\hline
\end{tabular}

Sampel yang memiliki nilai konduktivitas yang tertinggi pada lingkungan udara yaitu sampel $\mathrm{CuO}$ didoping $6 \%$ mol $\mathrm{ZnO}$ dengan nilai konduktivitasnya $7,69 \times 10^{-5} / \Omega \mathrm{m}$, hal ini disebabkan karena pada sampel $\mathrm{CuO}$ didoping $6 \%$ mol $\mathrm{ZnO}$ telah terjadi reaksi antara gas-gas yang terkandung di udara dengan oksida, sedangkan nilai konduktivitas tertinggi pada lingkungan hidrogen terdapat pada sampel $\mathrm{CuO}$ didoping $2 \%$ mol $\mathrm{ZnO}$ yaitu $21,91 \times 10^{-5} / \Omega \mathrm{m}$, hal ini terjadi karena penambahan doping yang dapat menurunkan energi gap.

\subsection{Karakteristik Waktu Respon}

Waktu respon sebuah sensor gas sangat penting untuk diketahui, karena dengan menghitung waktu respon dapat diketahui kemampuan suatu sensor gas dalam mendeteksi gas tertentu disekitarnya. Waktu respon diukur pada sampel yang memiliki nilai sensitivitas tertinggi yaitu sampel $92 \%$ mol $\mathrm{CuO}$ didoping $8 \%$ mol $\mathrm{ZnO}$ pada tegangan operasional $21 \mathrm{Volt}$. Grafik hasil pengukuran waktu respon dapat dilihat pada Gambar 4.

Pengukuran arus untuk menentukan waktu respon dilakukan tiap $3 \mathrm{~s}$ di lingkungan udara hingga stabil, kemudian setelah di udara dilanjutkan dengan mengalirkan gas hidrogen sampai didapatkan nilai arus yang stabil. Sampel berada pada lingkungan udara hingga kuat arus stabil, kuat arus stabil sampai $60 \mathrm{~s}$. Gas hidrogen dialirkan dan terjadi peningkatan kuat arus yang signifikan. Sampel dibiarkan hingga kuat arus stabil pada 105 s. Nilai waktu respon didapatkan pada rentang waktu ketika sampel mulai di aliri gas hidrogen sampai kuat arus menjadi stabil. Dari hasil pengukuran didapatkan waktu respon $45 \mathrm{~s}$. 


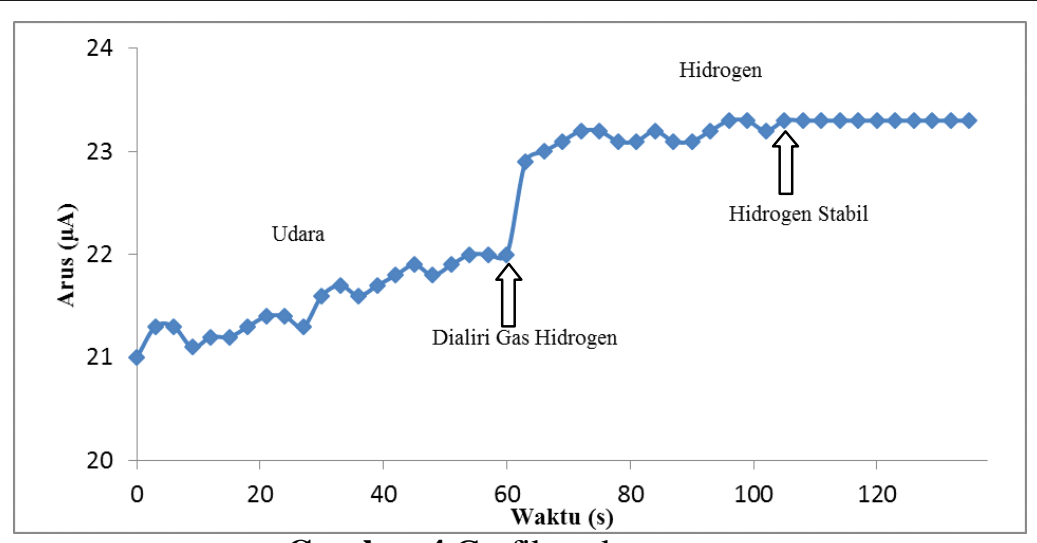

Gambar 4 Grafik waktu respon

\subsection{Karakteristik XRD}

Pengamatan struktur kristal, ukuran kristal dan senyawa yang terbentuk dalam material $\mathrm{CuO}$ tanpa doping dan $\mathrm{CuO}$ yang didoping $8 \%$ mol $\mathrm{ZnO}$ dilakukan menggunakan Difraksi Sinar-X (XRD). Hasil karakteristik dapat dilihat pada Gambar 5.

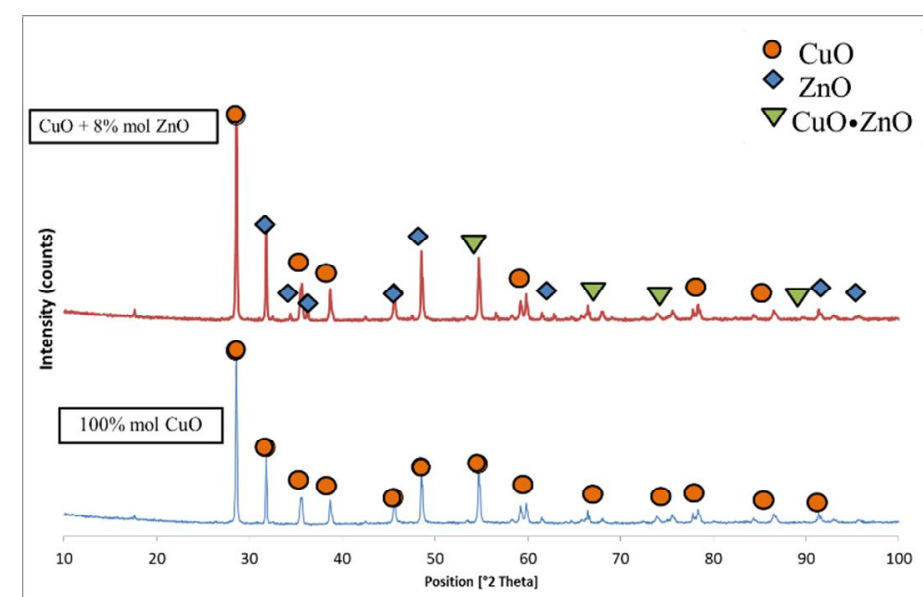

Gambar 5 Hasil uji difraksi sinar-X pada sampel $\mathrm{CuO}$ tanpa doping dan $\mathrm{CuO}+8 \%$ mol ZnO

Hasil XRD menunjukkan bahwa pada sampel $\mathrm{CuO}$ didoping $8 \%$ mol $\mathrm{ZnO}$ terdapat puncak-puncak baru yaitu $\mathrm{ZnO}$ dan $\mathrm{CuO} \cdot \mathrm{ZnO}$. Munculnya puncak-puncak baru menunjukkan terbentuknya senyawa yang baru. Penambahan $\mathrm{ZnO}$ juga mempengaruhi ukuran kristal. Ukuran kristal pada kedua sampel dihitung dengan menggunakan Persamaan 4, ukuran kristal 100\% mol $\mathrm{CuO}$ yaitu 128,33 nm. Ukuran kristal sampel $\mathrm{CuO}$ didoping $8 \%$ mol $\mathrm{ZnO}$ adalah 143,48 $\mathrm{nm}$, hal ini menunjukkan bahwa doping memperbesar ukuran kristal. Pada Gambar 5 terlihat bahwa sampel yang di XRD adalah sampel yang sensitivitas paling tinggi dan sensitivitas terendah. Sampel dengan sensitivitas paling tinggi memiliki ukuran kristal lebih besar dibandingkan dengan sampel yang sensitivitasnya rendah. Senyawa $\mathrm{ZnO}$ dan $\mathrm{CuO} \cdot \mathrm{ZnO}$ memiliki sistem kristal heksagonal sedangkan $\mathrm{CuO}$ dengan sistem kristal monoklinik.

\section{KESIMPULAN}

Pengujian sensor gas semikonduktor dimana sensor telah mampu membedakan antara kondisi di lingkungan udara dengan kondisi di lingkungan hidrogen. Nilai sensitivitas tertinggi didapatkan pada sampel $92 \%$ mol $\mathrm{CuO}$ didoping $8 \% \mathrm{~mol} \mathrm{ZnO}$ yaitu 4,59 pada bias maju, menggunakan tegangan operasional 21 Volt pada temperatur ruang. Nilai konduktivitas di lingkungan hidrogen lebih tinggi dibandingkan di lingkungan udara. Nilai Konduktivitas tertinggi terdapat pada sampel $98 \% \mathrm{~mol} \mathrm{CuO}$ didoping $2 \%$ mol $\mathrm{ZnO}$ yaitu $21,91 \times 10^{-5} / \Omega \mathrm{m}$ pada lingkungan hidrogen. Waktu respon pada sampel $92 \%$ mol CuO didoping $8 \%$ mol $\mathrm{ZnO}$ dengan lama waktu respon yaitu $45 \mathrm{~s}$ pada tegangan operasional 21 Volt. Hasil XRD menunjukkan 
bahwa ukuran kristal $\mathrm{CuO}$ didoping $8 \%$ mol $\mathrm{ZnO}$ yaitu $143,48 \mathrm{~nm}$ lebih besar dibandingkan dengan $\mathrm{CuO}$ tanpa doping yaitu sebesar $128,33 \mathrm{~nm}$.

\section{DAFTAR PUSTAKA}

Akbar, A.S., 1997, Sensing Mechanism of a Carbon Monoxide Sensor Based On Anatase Titania, Journal Electrochemistry Society, Vol 144 No 5, hal 1750-1753.

Aygun, S. dan Cann, D., 2005, Hydrogen Sensitivity of Doped CuO/ZnO Heterocontact Sensors, Sensors and Actuators B, Vol 106, hal 837-842.

Cao, Y., Pana, W., Zonga, Y dan Dianzeng, J, 2009, Preparation and Gas-Sensing Properties of Pure and Nd-doped ZnO Nanorods by Low-Heating Solid-State Chemical Reaction, Sensors and Actuators B, Vol 138, hal 480-484.

Fardindoost, S., Iraji, Z.A., Rahimi, F., d a n Ghasempour, R., 2010, Pd D oped $\mathrm{WO}_{3}$ Films Prepared by Sol-Gel Process for Hydrogen Sensing. Int. J. Hydrog. Energy, Vol 35, hal 854-860.

Hoa, N.D., An, S.Y., Dung, N.Q., Van Quy, N., dan Kim, D., 2010, Synthesis of P-Type Semiconducting Cupric Oxide Thin Films and their Application to Hydrogen Detection. Sensors andActuators B, Vol 146 , hal 239-244.

Keenan, C.W., 1980, Ilmu Untuk Kimia Universitas, Jilid 1, Edisi Keenam, Erlangga, Jakarta.

Liu, Y., Hao, L., Gao, W., Wu, Z., Lin, Y., Li, G., Guo, W., Yu, L., Zeng, H., Zhu, J., dan Zhang, W., 2015, Hydrogen Gas Sensing Properties of $\mathrm{MoS}_{2} / \mathrm{Si}$ Heterojunction, Sensors and Actuators, Vol 211, hal 534-543.

Wang, C.C., Akbar, S.A., dan Madau, M.J., 1998, Ceramic Based Resistive Sensor, Journal of electroceramics, Vol 2 No 4, hal 273-282.

Wismadi, T., 2001, "Pembuatan dan Karakterisasi Lapisan Tipis Copper Oxide (CuO) Sebagai Sensor Gas", Skripsi, Program S-1 Fisika, Fakultas Matematika dan Ilmu Pengetahuan Alam, Institut Pertanian Bogor, Bogor. 